\section{The biocompatibility of porous vs non-porous bone cements: a new methodological approach}

\author{
C. Dall'Oca, ${ }^{1}$ T. Maluta, ${ }^{1}$ F. Cavani, ${ }^{2}$ \\ G.P. Morbioli, ${ }^{3}$ P. Bernardi, ${ }^{4}$ A. Sbarbati, ${ }^{4}$ \\ D. Deg|'Innocenti, ${ }^{1}$ B. Magnan'
}

'Department of Surgery, Orthopaedic and Traumatology Clinic, University of Verona 2Department of Anatomy and Histology, University of Modena

${ }^{3}$ Interdepartmental Center of Scientific

Research on Laboratory Animals (CIR-

SAL), University of Verona

${ }^{4}$ Department of Neurological,

Neuropsychological, Morphological and

Motor Sciences, University of Verona, Italy

\section{Abstract}

Composite cements have been shown to be biocompatible, bioactive, with good mechanical properties and capability to bind to the bone. Despite these interesting characteristic, in vivo studies on animal models are still incomplete and ultrastructural data are lacking. The acquisition of new ultrastructural data is hampered by uncertainties in the methods of preparation of histological samples due to the use of resins that melt methacrylate present in bone cement composition. A new porous acrylic cement composed of polymethylmetacrylate (PMMA) and $\beta$-tricalciumphosphate $(\beta$-TCP) was developed and tested on an animal model. The cement was implanted in femurs of 8 New Zealand White rabbits, which were observed for 8 weeks before their sacrifice. Histological samples were prepared with an infiltration process of LR white resin and then the specimens were studied by X-rays, histology and scanning electron microscopy (SEM). As a control, an acrylic standard cement, commonly used in clinical procedures, was chosen. Radiographic ultrastructural and histological exams have allowed finding an excellent biocompatibility of the new porous cement. The high degree of osteointegration was demonstrated by growth of neo-created bone tissue inside the cement sample. Local or systemic toxicity signs were not detected. The present work shows that the proposed procedure for the evaluation of biocompatibility, based on the use of LR white resin allows to make a thorough and objective assessment of the biocompatibility of porous and non-porous bone cements.

\section{Introduction}

In orthopedic clinic, polymethylmetacrylate (PMMA) was first used for prostheses fixation and as a bone substitute. ${ }^{1}$ More recently, the indications to the use of this material have been extended to transpedicular vertebroplasty, ${ }^{2}$ osteoporotic compression fractures ${ }^{3-7}$ and screws augmentation. ${ }^{8}$ All PMMA-based cements have excellent mechanical properties, radiopacity and generally are easy to use. ${ }^{9}$. The negative characteristics of PMMA-based bone cements are the strongly exothermic reaction, toxic effects of the monomer, inability to bind to bone and eventual induction of foreign bodygranulomas. ${ }^{10-12}$ The development of a fibrous tissue layer at the interface and bone reabsorption was also described. ${ }^{13,14}$ In order to avoid the disadvantages linked to the use of PMMA, new generations of bioactive bone cements have been developed. ${ }^{15}$ Calcium phosphatebased cement (CPC) has been tested and clinically used as bony filler in traumatic bone loss for its excellent self-setting ability, biocompatibility, partial osteoconductivity and bioresorbability. However, CPC has poor mechanical characteristics (e.g., compression strength). In addition, its handling problems and limited radiopacity prevents extended clinical uses. ${ }^{16-21}$ Composite cements (i.e., a mixture of acrylic cement and a ceramic component) have been shown to be biocompatible, bioactive and with good mechanical properties. ${ }^{22,23}$ In general, these materials demonstrate improved capability to bind to the bone. ${ }^{24}$ Despite these interesting characteristic, in vivo studies on animal models are still incomplete and, in particular, ultrastructural data are lacking. Information about such a structural organization cannot be obtained by means of biochemical techniques or optical microscopy, but requires ultrastructural evaluations, as demonstrated for adipose tissue. ${ }^{25}$ Ultrastructural data can be useful to understand the mechanisms of interaction between cements and the host tissue and to evaluate more correctly the suitability of cements for a particular purpose.

In the present study, we have developed a new procedure for testing acrylic cements in an in vivo animal model. For this purpose, we have used a new porous acrylic cement composed of PMMA and $\beta$-tricalciumphosphate $(\beta$ TCP). ${ }^{26,27}$ The study was conducted by an experimental procedure that allows to avoid uncertainties in the methods of preparation of histological samples due to use of chemicals that melt methacrylate present in bone cement composition. The method that we propose is based on an embedding in LR white resin, which is more commonly used in histochemical studies. This approach improves the visualization of the bone-cement interface adding
Correspondence: Carlo Dall'Oca, Department of Surgery, Orthopaedic and Traumatology Clinic, University of Verona, Ospedale Borgo Trento, Piazzale A. Stefani 1, 37126 Verona, Italy. Tel. +39.045 .8123542 - Fax: +39.045 .8027470 . E-mail: carlo.dalloca@univr.it

Key words: calcium phosphate cement, osteointegration, biocompatibility, osteoconduction, porosity.

Acknowledgments: the authors wish to thank the company Tecres SpA, Sommacampagna (Italy) for providing the cements used in this trial.

Received for publication: 20 July 2013. Accepted for publication: 25 February 2014.

This work is licensed under a Creative Commons Attribution NonCommercial 3.0 License (CC BYNC 3.0).

(C) Copyright C. Dall'Oca et al., 2014

Licensee PAGEPress, Italy

European Journal of Histochemistry 2014; 58:2255 doi:10.4081/ejh.2014.2255

new data on the behavior of an important component of therapy.

\section{Materials and Methods}

\section{Bone cements}

Two types of bone cement were used, both made from PMMA and $\beta$-TCP but with different physical-chemical characteristics. For the control group, it was assumed to use cement with balanced chemical, biological and physical characteristics, widely used in clinical practice. To meet these requirements, we chose a cement used in vertebroplasty as Mendec $^{\circledR}$ Spine (Tecres SpA, Sommacampagna, Italy) (NP cement). For the experimental group, a cement was realized, which present the characteristics of porosity, with the purpose of studying the behavior of bone tissue from the ultramicroscopic point of view (Porosectan ${ }^{\circledR}$ Tecres SpA) (P cement). Cements have been formulated and used in both liquid and in powder preparation and their composition is shown in Table 1.

All experiments were performed according to the following ISO norms: UNI EN ISO 10993-6 (2007): Test of local effects after implantation; UNI EN ISO 10993-1 (2004): Biological evaluation of medical devices. Part 1 Evaluations and testing; and UNI EN ISO 10993-12 (2005): Sample and reference materials.

\section{Animal experiments}

Cements were implanted in New Zealand White (NZW) rabbits, which were sacrificed after eight weeks. The animals used were eight 
female rabbits weighting between $2.9 \mathrm{Kg}$ and $3.6 \mathrm{Kg}$ before the beginning of the study. The rabbits were reared and operated at the Interdepartmental Center of Scientific Research on Laboratory Animals (Centro Interdipartimentale per la Ricerca Scientifica su Animali da Laboratorio, CIRSAL, University of Verona). The breeding conditions were in accordance with the European Directives (CE Directive 86/609) and UNI EN ISO 10993-2 (2006): Animal welfare requirement. The rabbits were bred in an individual metallic cage (Tecniplast ${ }^{\circledR}$, according to D.Lgs 116/02) and fed with complete granular diet for rabbits, ad libitum. Water was freely accessible. Temperature was between $15^{\circ}$ to $21^{\circ} \mathrm{C}$ and room relative dampness was between $30 \%$ to $70 \%$. The operative staff was qualified and educated. Both femurs of each rabbit were operated in different operating times, 2 weeks apart one after the other, in order to reduce the toxicity due to the anesthesia and to an excessive dosage of the acrylic cement. The NP cement was injected in the right femur whereas the new experimental cement into the left femur after 2 weeks.

\section{Animal preparation and anesthesia}

After trichotomy of concerned area, the rabbit was brought into operating room and positioned supine on the operating table. General anesthesia induction was carried out by a veterinarian, with intramuscular injection of an association of tiletamine hydrochloride and zolazepam hydrochloride (Zoletil $100 \AA$ ) at a dose of $20 \mathrm{mg} / \mathrm{Kg}$ and Xylazione (Rompun ${ }^{\circledR}$ ) at a dose of $5 \mathrm{mg} / \mathrm{Kg}$. A local anesthesia with lidocaine was also injected in the site of the surgical incision.

\section{Surgical procedures}

After washing, disinfection and preparation of sterile operating field, we made a longitudinal skin incision on lateral surface of femoral condyle, with exposition of troclea gorge, after patellae dislocation. The region was then washed with physiological saline. The femoral bone marrow channel was drilled with sterile electrical drill ( $\emptyset 4 \mathrm{~mm}$, dept 3-4 cm). After drilling, we washed and cleaned the hole to remove every bone parts created. We filled the femoral cavity with $0.5-1$ cc of acrylic cement with an appropriate syringe (the cement was injected in femoral distal epiphysis where cortical and spongious bone tissues were present). We reduced the dislocation and we did articular capsule suture with reabsorbable spin or Vicryl ${ }^{\circledR} n^{\circ} 3-0$ and skin suture with not reabsorbable spin Prolene ${ }^{\circledR} n^{\circ} 3-0$. We made an elastic adhesive bandage, after final disinfection. Analgesic therapy with Altadol ${ }^{\circledR}$ IM (4 $\mathrm{mg} / \mathrm{Kg}$ ) was administrated to the rabbits, after that the animals were located under UV lamp for $10 \mathrm{~min}$, before returning in their cage.

\section{Post-operative clinical follow-up}

Animals were observed daily to detect clinical abnormalities and antibiotic therapy was administrated for four days (Baytril ${ }^{\circledR} 2.5 \%$ SC 5 $\mathrm{mg} / \mathrm{Kg}$ ). Medications with antiseptic iodate $\left(\right.$ Braunol $^{\circledR}$ ) were done, and 10 days after surgery, cutaneous stitches are removed.

The rabbits state of well-being was assessed with physiological elements (feeding, stool and urine), physical elements (functions of operated limb and coat growth) and behavior elements, like open field. This test, known as escape test, is an indication of fear response (rabbit is prey animal, with avoidance reactions, like fear of new situations and human presence).

\section{Animals sacrifice}

Rabbits were sacrificed through pharmacology euthanasia with a lethal injection of Tanax $^{\circledR}$ after 8 weeks. Femurs were extracted from thigh, bone curettage from soft tissues was carried out and then all bones were put inside a transparent sterile envelope.

\section{Radiographic examination}

A radiographic examination was carried out using a Philips Practix 360 mobile radiography system. It consisted of antero posterior and lateral side of left and right femur of each rabbit.

\section{Ultrastructural analysis of cement porosity}

With the purpose of comparing their physical structure, cements were subjected to structural analysis with scanning electron microscope (SEM), which has a high depth of field and allow a good visualization of eventual porosity. To obtain a correct analysis of the surface, the samples were maintained under vacuum (10-5 Torr) and covered by a layer of con- ductive metal to avoid electrostatic charge. Therefore, samples were covered with a thin layer of gold by a sputtering coater MED 010 (Balzers). A DSM 950 (Zeiss) SEM was used for ultrastructural examination.

\section{Histological samples preparation}

Rabbit's femurs were fixed in buffered formaldehyde ( $\mathrm{pH}=7)$ for 3 days. Every femur distal third was pulled out and treated with resin inclusion according to the following protocol:

- progressive dehydration in ethyl alcohol at progressive gradation (50\%, 70\%, 80\%, 95\%, absolute) leaving the sample for at least 3 days in every alcohol, three passage in absolute ethanol;

- infiltration with LR white resin, three passages for a total time of 15 days.

resin polymerization.

Since all resins, used for the infiltration required for histological cutting, dissolved the methacrylate used in the cement, we searched for a resin allowing cement to resist and do not dissolve under long infiltration periods. For this purpose, we chose LR white resin and an infiltration time compatible with inclusion quality has been established as mentioned above. The samples were cut by a circular microtome for bone (Leitz 1660) according to a plane perpendicular to the femur axis obtaining $100 \mu \mathrm{m}$ thick sections. These sections were stained by immersion in a blue of toluidine solution (basic color that evidence cellular nucleus and cartilage) for 5 min and, after water washing, they were immersed in a fast green solution (color that evidences the bone) for $2 \mathrm{~min}$. After further water washing, the sections were quickly dehydrated by immersion in progressive graded alcohol solutions. After this operation, sections were put on slide holders with DPX for optical microscope observation.

Table 1. Tested bone cements composition and some chemical-physical characteristics.

\begin{tabular}{|c|c|c|}
\hline & \multicolumn{2}{|c|}{ Cements } \\
\hline & $\begin{array}{l}\text { Non porous cement } \\
\text { or NP cement } \\
\text { (Mendec @ Spine) }\end{array}$ & $\begin{array}{l}\text { Porous cement } \\
\text { or P cement } \\
\text { (Porosectan } ®)\end{array}$ \\
\hline Powder package & 20 g powder & 20 g powder \\
\hline Powder composition & $\begin{array}{l}\text { - Polymethylmetacrylate } 67.5 \% \\
\text { - Barium solphate } 30,0 \% \\
\text { - Benzoyl peroxide } 2.50 \%\end{array}$ & $\begin{array}{c}\text { - Polymethylmetacrylate } 65.0 \% \\
\text { - } \beta \text {-TRICALCIUM PHOSPHATE 30.0\% } \\
\text { - Barium sulphate } 5.0 \%\end{array}$ \\
\hline Liquid package & $9.4 \mathrm{~g}$ phial & $5.0 \mathrm{~g}$ phial \\
\hline Liquid composition & $\begin{array}{l}\text { - Methylmetacrylate } 99.10 \% \\
\text { N-N dimethyl-p-toluidines 0.90\% } \\
\text { - Hydroquinone } 75 \text { ppm }\end{array}$ & $\begin{array}{c}\text { - Methylmetacrilate } 98.20 \% \\
\text { - N-N dimethyl-p-toluidines 1.80\% } \\
\text { - Hydroquinone } 75 \text { ppm }\end{array}$ \\
\hline Setting time & $21-25 \min$ & $9 \min$ \\
\hline Max. polimerization temperature & $70^{\circ} \mathrm{C}$ & $44^{\circ} \mathrm{C}$ \\
\hline Max water absorption & $3 \%$ & $20 \%$ \\
\hline
\end{tabular}




\section{Evaluation of osteoconductivity}

All samples were examined under an optical microscope (Eclipse 80i, Nikon). For this examination, the middle section of each series obtained from the area filled with cement was used. Regenerated bone was distinguished from original based on histological features, namely the staining and different morphologies of bone cells and matrix. Computer-assisted histomorphometric measurements of the implanted cements and soft tissues were also performed using an image analyzer (Image J, $\mathrm{NIH})$. The affinity index of each cement was calculated on basis of regenerated bone areas as a percentage of the total cement area. The data obtained were compared using one-way analysis of variance (ANOVA). P-values $<0.05$ were considered statistically significant. ${ }^{28}$

\section{Results}

\section{Chemical-physical and mechanical performances of cements}

The ISO 5833 norm was followed to describe the chemical-physical performances (Table 1) and static mechanical performances (Table 2) of both medical devices. Water absorption was also calculated evaluating the increase in weight following $30 \mathrm{~min}$ of immersion in saline solution. $\mathrm{P}$ cement has a quicker setting time (9'vs 21'-25'), a lower polymerization temperature $\left(44^{\circ} \mathrm{C}\right.$ vs $\left.70^{\circ} \mathrm{C}\right)$ and higher water absorption (20\% vs 3\%) compared to NP cement.

Static mechanical performances of $\mathrm{P}$ cement are markedly lower compared to NP cement: compression 50MPa vs $100 \mathrm{MPa}$, bending strength $22 \mathrm{MPa}$ s $50 \mathrm{MPa}$ and bending modulus $900 \mathrm{MPa}$ ss $3100 \mathrm{MPa}$.

\section{Clinical follow-up}

The surgery procedure was well-tolerated and the animals managed to feed himself since the day after the operation. Within a few days, they managed to move again inside the cage. The effects due to the introduction of the cement and to his following polymerization were hypotension/low heart rate: these effects have been noticed during the surgery session and were similar for both the bone cements. Neither signs of local swelling or inflammation, nor systemic signs of cement-toxicity or allergic reactions were found. All the animals subjected to the operation survived.

\section{Macroscopic examination}

After the removal of the femur, the injection area was well-visible. To the touch, the surface of the $\mathrm{P}$ cement appeared rougher than those of NP cement. In addition, the surface P cement could easily be scratched with the scalpel.

\section{Radiographic examination}

In NP cement samples, post-mortem radiographic examination of the removed femurs demonstrated, a reduced radio-opacity, probably due to the lower quantity of barium (Figure $1 \mathrm{~A}, \mathrm{~B})$. In P cement scaffold there were granulous-like radio-opaque spots resembling to NP cement specimens implanted in the other femur. These radio-opaque spots, resembling NP cement in term of density, were probably due to the presence of PMMA. In fact, the other component of the NP cement (i.e., the $\beta$-TCP) is rapidly reabsorbed being quickly dissolved (more than hydroxyapatite present in other cements) and it is partially substituted by bone tissue, whereas PMMA is not reabsorbable.

\section{Scanning electron microscope observations}

At scanning electron microscope (SEM) examination, $P$ cement's surface resulted very porous and characterized by a stringy appearance, with interconnected volumes and with the presence of many microreliefs, cavities and pores (Figure 2 A,B). Typical spherical par- ticles, characterized by a diameter of about 40 $\mu \mathrm{m}$, were evident inside the cement agglomeration. Probably, they were particles of PMMA, previously treated because of their incompatibility with tricalcium-phosphates. In P cement, micropores and macropores characterize the surface. The average diameter of the micropores varies from 10 to $15 \mu \mathrm{m}$; the macropores go from 100 to $250 \mu \mathrm{m}$. It could be remembered that a similar situation exists in the spongious bone where trabeculae are within about 200 $300 \mu \mathrm{m}$ one another. On the contrary, as we can notice from the pictures (Figure $3 \mathrm{~A}, \mathrm{~B}$ ), NP cement's surface results solid, predominantly sleek and with a rare presence of pores: the gaps, evident on the surface, are probably artifacts due to the technical treatments.

\section{Evaluation of osteoconductivity}

The affinity indices (\%) for the P cement and the NP cement at each month are shown in the graph (Figure 4). Their averages were $80.01( \pm 4.3)$ and $21.24( \pm 1.8)$, respectively. These differences were statistically significant $(\mathrm{P}>0.01)$.

Table 2. Tested bone cements mechanical properties compared to mature bone.

\begin{tabular}{lccc} 
Cements & Compression strength & Bending strength & Bending modulus \\
NP cement & $100 \mathrm{MPa} \pm 8 \mathrm{MPa}$ & $50 \mathrm{MPa} \pm 5 \mathrm{MPa}$ & $3100 \mathrm{MPa}$ \\
P cement & $50 \mathrm{MPa} \pm 8 \mathrm{MPa}$ & $22 \pm 5 \mathrm{mpA}$ & $90 \mathrm{MPa}$ \\
\hline Mature bone & Femur $167 \mathrm{MPa}$ & Not applicable & $6000 \mathrm{MPa}$ \\
& $\begin{array}{c}\text { Humerus } 130 \mathrm{MPa} \\
\text { Vertebra } 7 \mathrm{MPa}\end{array}$ & \\
\hline
\end{tabular}

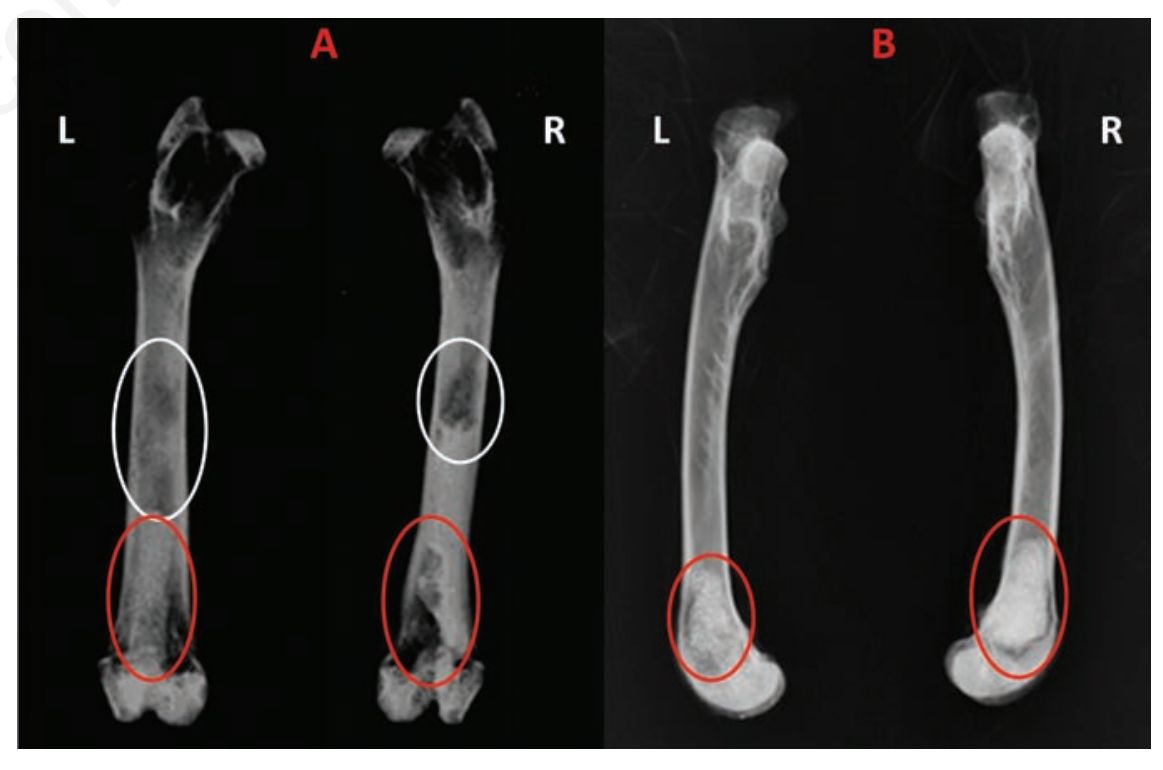

Figure 1. X-rays: antero posterior (A) and lateral side $(B)$ of right $(\mathrm{R})$ and left $(\mathrm{L})$ femur. Left femur (L) with the $P$ cement and right femur ( $R$ ) with NP cement. In NP cement samples, post-mortem radiographic examination of the removed femurs demonstrated a reduced radio-opacity, probably due to the lower quantity of barium (white circle). In $P$ cement scaffold there were granulous-like radio-opaque spots resembling to NP cement specimens implanted in the other femur (red circle). 


\section{Histological examination}

As expected, LR white resin the resin did not melt the methacrylate in the infiltration treatment. It was not possible to cut sections thinner than $100 \mu \mathrm{m}$, and some sections are came unstuck during the cut. Because DPX and xylene, indispensable to create the slides, melt the cement, cement casting out of its limit was found in some slides. However, areas close to cement, were well preserved and surface color allowed to evaluate tissues near to the cement.

Histological analysis allowed to distinguish, on the basis of their density, the acrylic cement (NP cement) (Figure $5 \mathrm{~A}, \mathrm{~B}$ ) from the P cement (Figure $5 \mathrm{C}, \mathrm{D}$ ); the first presented a structure denser and more homogeneous than the second, which showed a more inhomogeneous and irregular structure. In the histological sections, in both the cements, the outline of the hole, made with the operating drill, appeared always evident (Figure 5 A,C). The cement resulted regularly and clearly surrounded by circular-course trabeculae of bone (rather than radial-course ones visible in absence of cement). These features demonstrate that new bone tissue is formed around the cement. Some trabeculae of bone and neo-created areas of connective tissue were also evident in $P$ cement. They penetrated the superficial pores of the cement (Figures $6 \mathrm{~A}, \mathrm{~B}, 7,8 \mathrm{~A}-\mathrm{C}$ ). These structures entered the cement for about $250 \mu \mathrm{m}$ average in depth (Table 3 ). The measures made in these areas demonstrated that the bone keeps on growing until a depth of maximum $400 \mu \mathrm{m}$. The observation under polarized light confirmed that it is actually bone tissue and not an artifact due to the toluidine blue, which sometimes penetrates the cavities giving the impression that the neocreated bone stays inside the cement (Figure 6 $A, B)$. According to the size of the bone-filled cavities, there was evidence that their diameter varies approximately from $30 \mu \mathrm{m}$ to 150 $\mu \mathrm{m}$ : these holes almost correspond to the dimensions of the cement's superficial cavities visible at SEM examination. The osteoconductivity of P cement, due to its open macroporous structure, allowed the bone cells and the blood vessels to colonize superficially the bone gap left by the $\mathrm{P}$ cement reabsorption; it also probably permitted to the osteoblasts to re-create homogeneously the bone tissue only at the bone-cement interface (Figure 6A).

The sample of NP cement, according to its low porosity, did not show penetration of any type of material. Moreover, around the samples where the P cement was used, there was no result of any bone or connective tissue proliferation. This aspect was probably due to the high density of the material that allowed only a limited penetration of fibrous tissue in rare microsplits (Figure 7). In P cement, the presence of stained areas, which go deeper from the outside

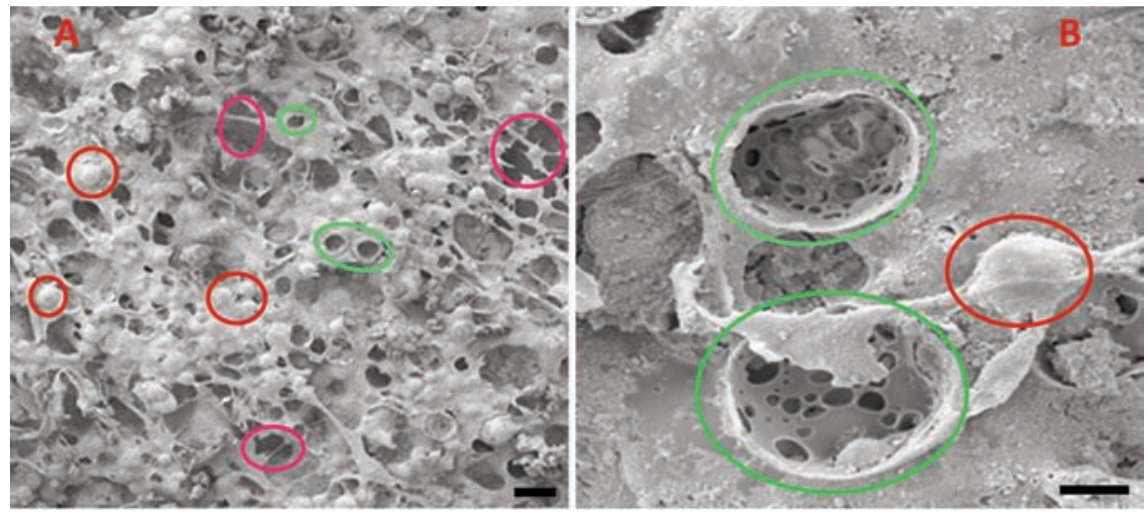

Figure 2. SEM examinations of $P$ cement surface. $P$ cement surface resulted very porous and characterized by a stringy appearance, with interconnected volumes and with the presence of many microreliefs (red circles), cavities (violet circles) and pores (green circles). Typical spherical particles, characterized by a diameter of about $50 \mu \mathrm{m}$, were evident inside the cement agglomeration. In $\mathrm{P}$ cement, the surface is characterized by micropores and macropores. Scale bars: A), $100 \mu \mathrm{m} ; \mathrm{B}), 20 \mu \mathrm{m}$.
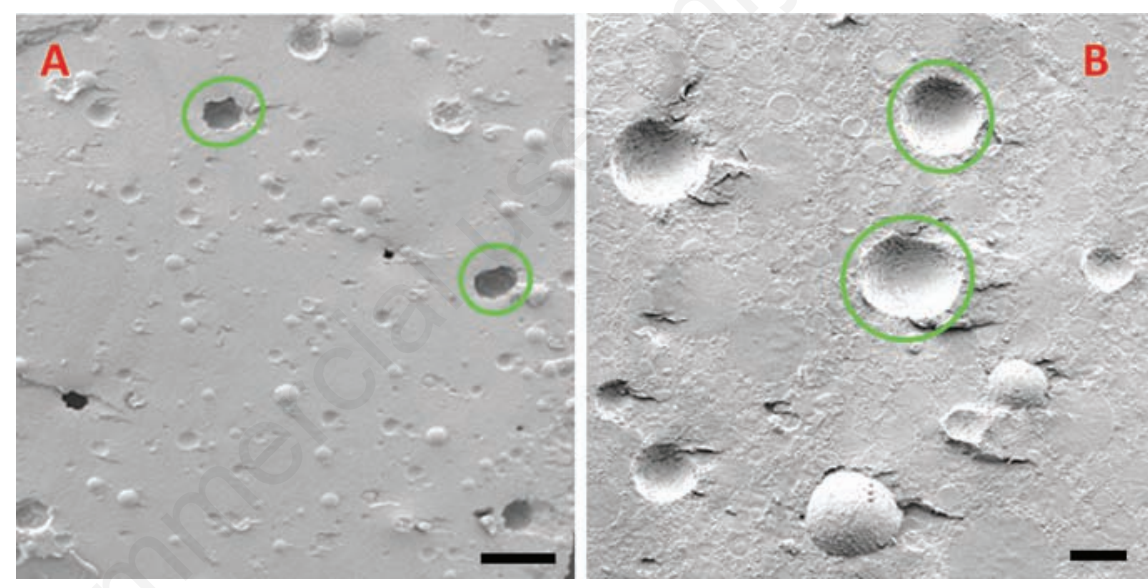

Figure 3. SEM examinations of NP cement surface. NP cement surface results solid, predominantly sleek and with a rare presence of pores (green circles): the gaps, evident on the surface, are probably artifacts due to the technical treatments. Scale bars: A), $250 \mu \mathrm{m}$; B), $50 \mu \mathrm{m}$.

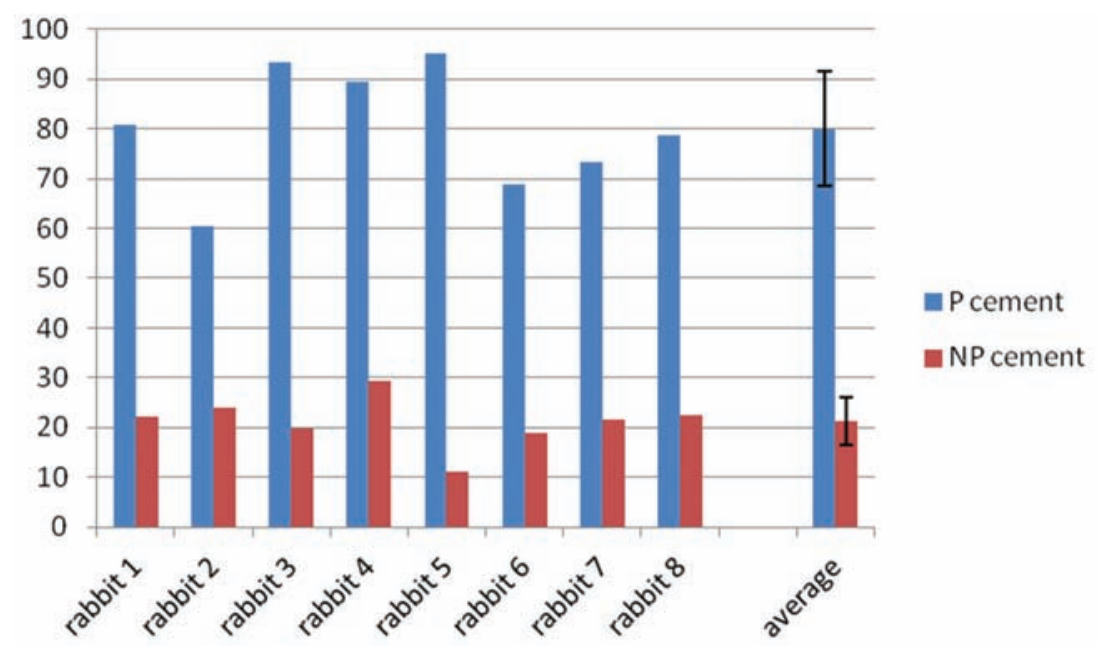

Figure 4. Affinity indices of the P cement and the NP cement in 8 rabbit samples. The average value were 80.01 and 21.24 , with a standard deviation of 12.24 and 6.04 , respectively for P cement and NP cement. 
to the central zone (Figure $8 \mathrm{~A}-\mathrm{C}$ ), indicates the porosity of the cement, but it was not clear if osteoblasts penetrated in the cement from nearly bone or if they are generated by a proliferation inside the matrix (bone neo-creation). It has to be noticed that $\mathrm{P}$ cement did not show superficial pores in the entire bone-cement interface. In some areas the surface appeared devoid of pores: in these areas, the surrounding bone behaves as it does around NP cement (i.e., it did not penetrate the cement). Probably, this result was due to the superior density of PMMA belonged to these zones. A reasonable explication of this superior density is that PMMA did not amalgamate well during the mixing of the cement. About the analysis of the soft tissues, it is important to underline that the type of technical approach used in this study has not allowed keeping them well-preserved in all the areas. In this research, the preservation of the cement and of the bone was privileged. Anyway, the observation of the areas that resulted less damaged by the resin indicated that the cements used cause neither necrosis nor inflammation of the surrounding soft tissues. In both the analyzed samples, there was generally no evidence of any significant inflammatory reaction, necrosis or fibrosis of the surrounding bone tissue.
Table 3. Samples histological evaluation: osteointegration and cement penetration depth in bone.

\begin{tabular}{|c|c|c|c|}
\hline N. & $\begin{array}{l}\text { NP cement } \\
\text { Right femur }\end{array}$ & $\begin{array}{l}\text { P cement } \\
\text { Left femur }\end{array}$ & $\begin{array}{l}\text { Penetration depth } \\
\text { of cement }\end{array}$ \\
\hline 1 & Osteointegration & $\begin{array}{l}\text { Osteointegration + superficial } \\
\text { penetration of bone in some } \\
\text { circumferential areas }\end{array}$ & $215 \pm 35 \mu \mathrm{m}$ \\
\hline 2 & Osteointegration & $\begin{array}{l}\text { Osteointegration + superficial } \\
\text { penetration of bone } \\
\text { in some circumferential areas }\end{array}$ & $330 \pm 70 \mu \mathrm{m}$ \\
\hline 3 & Osteointegration & $\begin{array}{l}\text { Osteointegration + superficial } \\
\text { penetration of bone } \\
\text { in some circumferential areas }\end{array}$ & $150 \pm 29 \mu \mathrm{m}$ \\
\hline 4 & Osteointegration & $\begin{array}{l}\text { Osteointegration + superficial } \\
\text { penetration of bone } \\
\text { in some circumferential areas }\end{array}$ & $244 \pm 41 \mu \mathrm{m}$ \\
\hline 5 & Osteointegration & $\begin{array}{l}\text { Osteointegration + superficial } \\
\text { penetration of bone } \\
\text { in some circumferential areas }\end{array}$ & $277 \pm 55 \mu \mathrm{m}$ \\
\hline 6 & Osteointegration & $\begin{array}{l}\text { Osteointegration + superficial } \\
\text { penetration of bone } \\
\text { in some circumferential areas }\end{array}$ & $240 \pm 30 \mu \mathrm{m}$ \\
\hline 7 & Osteointegration & $\begin{array}{l}\text { Osteointegration + superficial } \\
\text { penetration of bone } \\
\text { in some circumferential areas }\end{array}$ & $277 \pm 30 \mu \mathrm{m}$ \\
\hline 8 & Osteointegration & $\begin{array}{l}\text { Osteointegration + superficial } \\
\text { penetration of bone } \\
\text { in some circumferential areas }\end{array}$ & $270 \pm 49 \mu \mathrm{m}$ \\
\hline
\end{tabular}

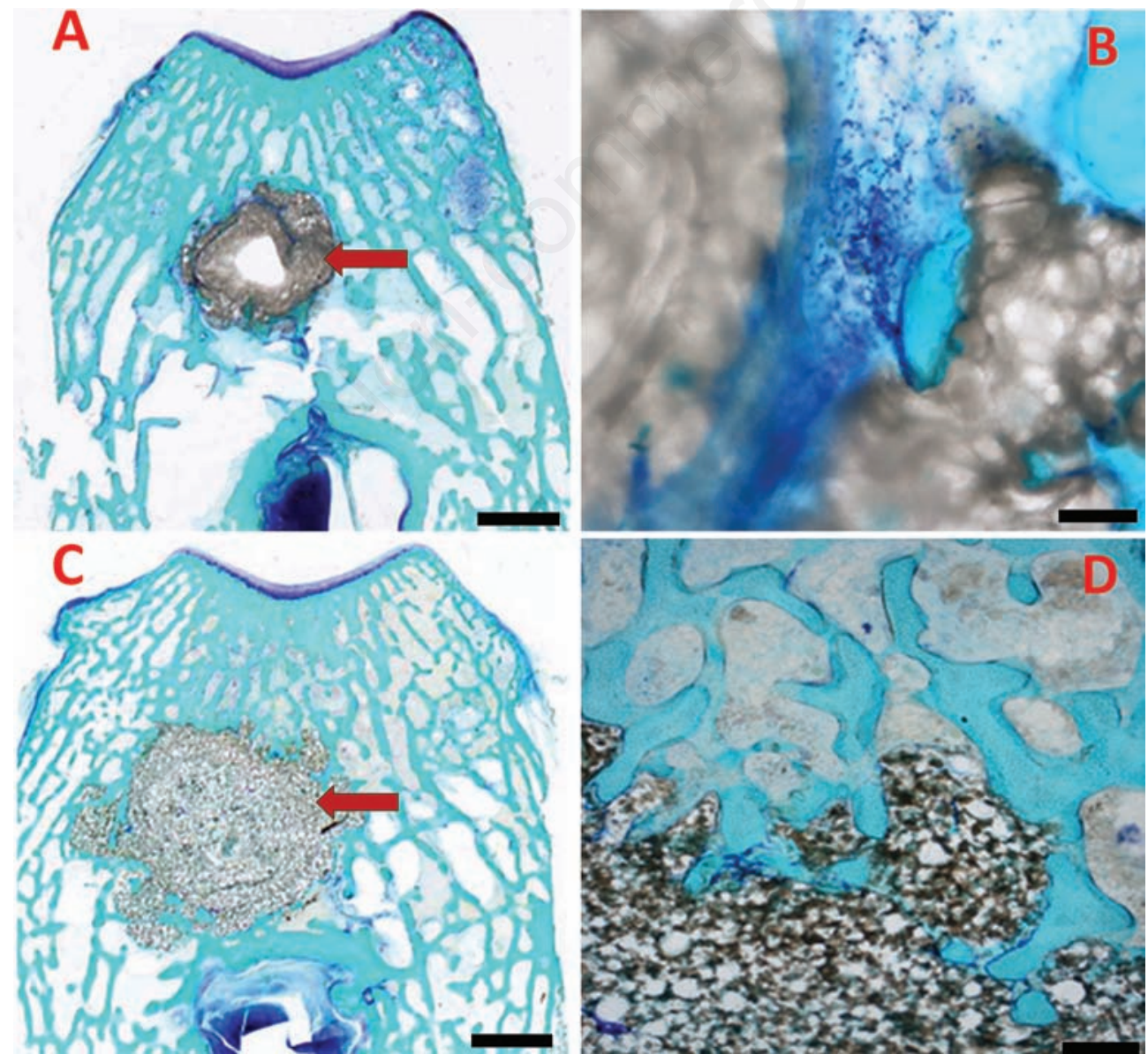

Figure 5. Histological sample of NP cement (A), its enlargement $(B), P$ cement $(C)$ and its enlargement (D). Histological analysis allowed to distinguish, on the basis of their density, the NP cement (A, B) from the $P$ cement $(C, D)$; the first presented a structure denser and more homogeneous than the second, which showed a more inhomogeneous and irregular structure. In the histological sections, in both the cements, the outline of the hole, made with the operating drill, appeared always evident. The cement resulted regularly and clearly surrounded by circular-course trabeculae of bone (rather than radial-course ones visible in absence of cement). These features demonstrate that new bone tissue is formed around the cement. Scale bars: A,C), $200 \mu \mathrm{m}$. B), $20 \mu \mathrm{m} ; \mathrm{D}), 40$ $\mu \mathrm{m}$. 


\section{Discussion}

Scientific publications relating to the evaluation of the in vivo biocompatibility of cements, show different approaches and results ${ }^{28-31}$ and in the present study we have assessed the biocompatibility of porous and non-porous cement. For this purpose, it is useful to note that signs of local or systemic toxicity were not found: in particular, neither inflammation nor infection were detected in the site of injection and no foreign body reaction was found. In addition, the histological examination showed no evidence of necrosis, inflammation or fibrosis areas. Therefore, the porous material that we have used revealed a biocompatibility comparable to those of traditional acrylic cement. Toxicity due to an eventual presence of monomer was not detected. In addition, the low polymerization temperature of the new material suggests that a lesser methylmethacrylate concentration than a traditional acrylic cement could have a role in decreases the eventual thermal necrosis of bone nearly the cement. In this site, the porous cement was surrounded by a layer of bone tissue, which appears to be a result of his low local toxicity. At radiological examination, its opacity was not much less than the control (NP cement), however some differences between the two cements were found (i.e. the first showed a showed a granulose texture, while the second appeared more compact. ${ }^{21}$ This aspect is probably related with the structure of this cement that is microscopically porous with an outbound opened structure. Through SEM analysis, we have seen that cement pores are about 150-200 $\mu \mathrm{m}$ diameter and they are interconnected creating a scaffold like hydroxyapatite in the spongious bone tissue. Therefore, they can be classified as macropores and they seem to be large enough to allow the penetrations of cells and even of vessels from the surrounding tissue. In addition, we observed the presence of micropores with a 10-15 $\mu \mathrm{m}$ diameter, which form interconnections between the bigger pores, creating a tridimensional scaffold that supply fluid penetration inside the matrix as demonstrated in vitro studies. ${ }^{32}$

At the histological examination, we observed that the porous cement is penetrated by bonelike matrix but only superficially till to $250 \mu \mathrm{m}$ average depth, demonstrating that its osteconductive property is only limited to the peripheral areas. We suppose that a deeper penetration of bone matrix might be considered available with cement characterised by bigger pores as suggested by Goto et al..$^{22}$ Despite this limit, the penetration possible because of the bind to bone characteristic of this cement, which contacted bone directly without fibrous tissue interposition is certainly of interest. The affinity index is a rate of this characteristic and it considers the
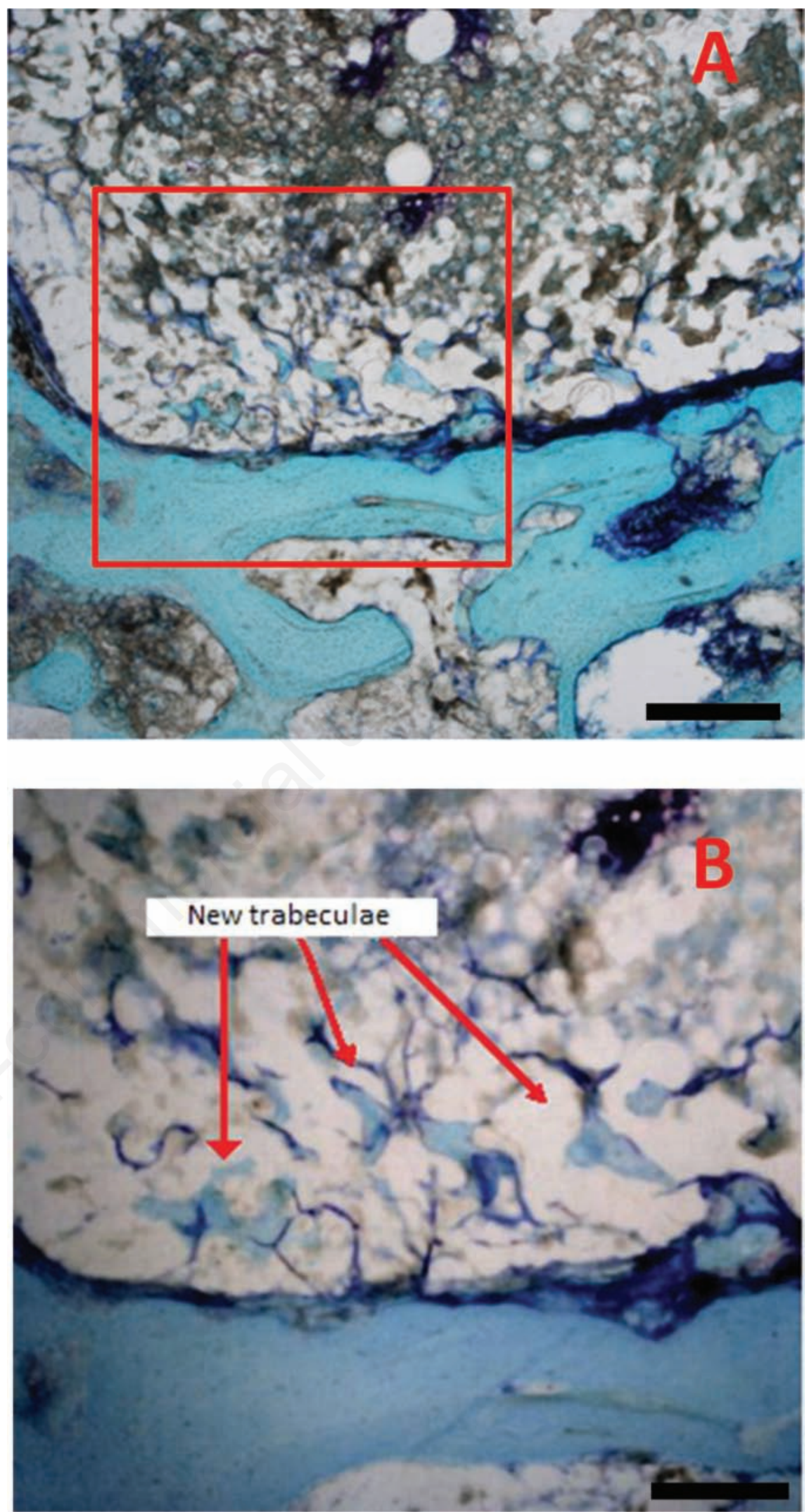

Figure 6. The presence of stained areas inside the cement at the interface ( $P$ cement). Some trabeculae of bone and neo-created areas of connective tissue were also evident in $\beta$-TCP/acrylic samples (P cement). They penetrated the superficial pores of the cement. Scale bars: A), $40 \mu \mathrm{m} ; \mathrm{B}), 20 \mu \mathrm{m}$. 
relationship between all the cement area and the cement surface in contact directly with bone.

In literature is reported that PMMA-affinity indices are less than the ones of TCP-based cements; the present work suggests that this aspect could be related to the formation of a fibrous layer between the PMMA surface and bone, which is typical of a foreign body reaction. TCP-based cement is partially reabsorbed by osteoclastic elements and this reaction lead to the release of calcium and phophorous ions, which could promote the bone apposition..$^{16}$ As regards the affinity index, the results of the present study are quite consistent with those obtained by Goto et al..$^{22}$ Other type of cements, (e.g., methacrylate cement with AW-glass ceramic, hydroxyapatite or $\beta$-TCP fillers) are described in literature ${ }^{33,34}$ binding to bone directly but a thinner calcium-phosphate rich layer is reached using these material than using a TCP/acrylicbased cement. The affinity indices of these materials are also reported to be lower than obtained using porous cement giving a measure of its biocompatibility.

Additional considerations emerge from the

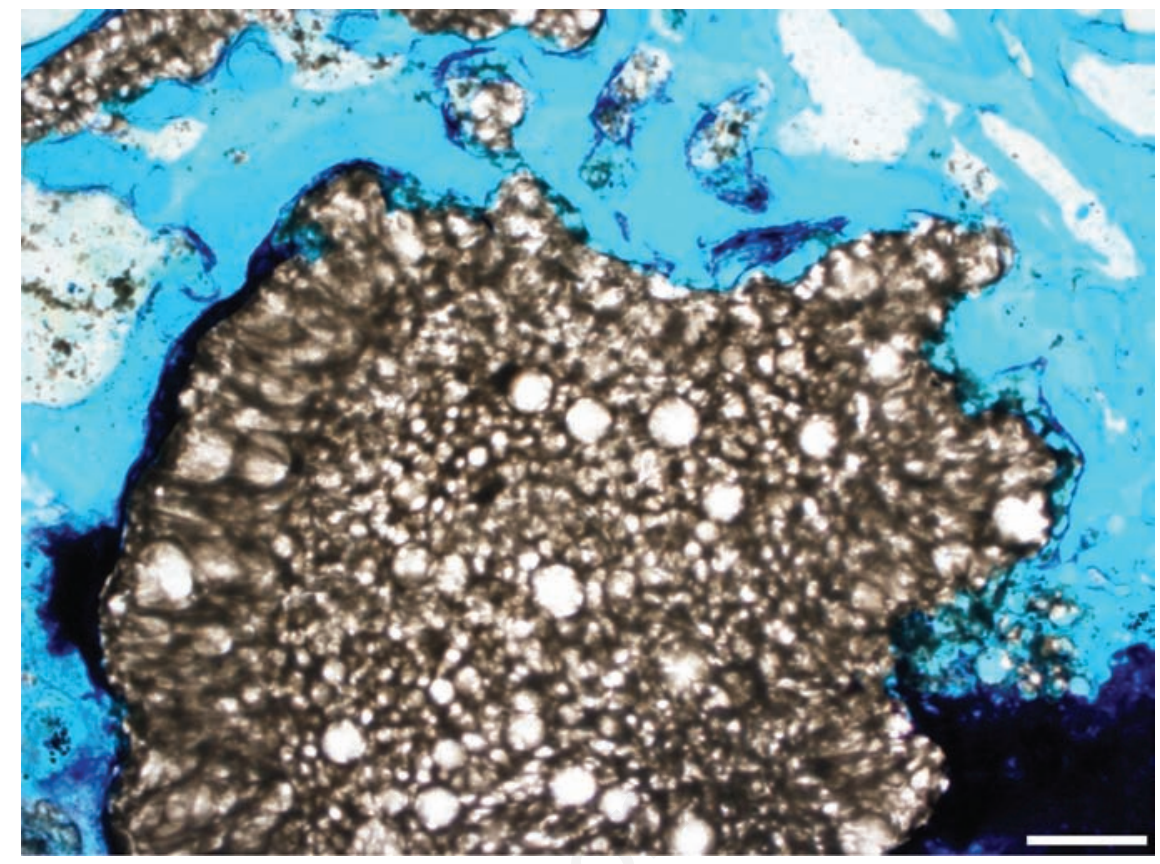

Figure 7. Histological sample of NP cement. Scale bar: $40 \mu \mathrm{m}$.
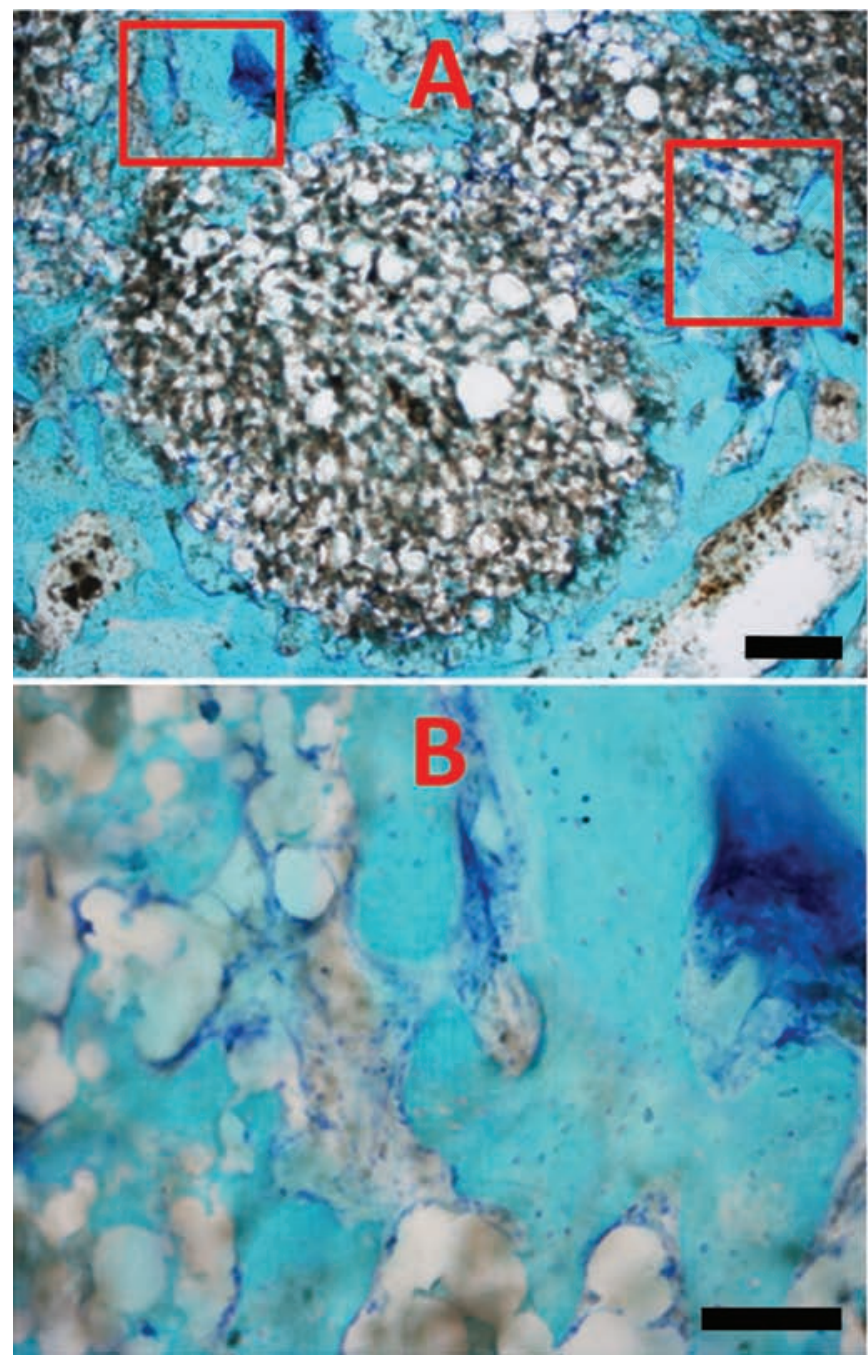

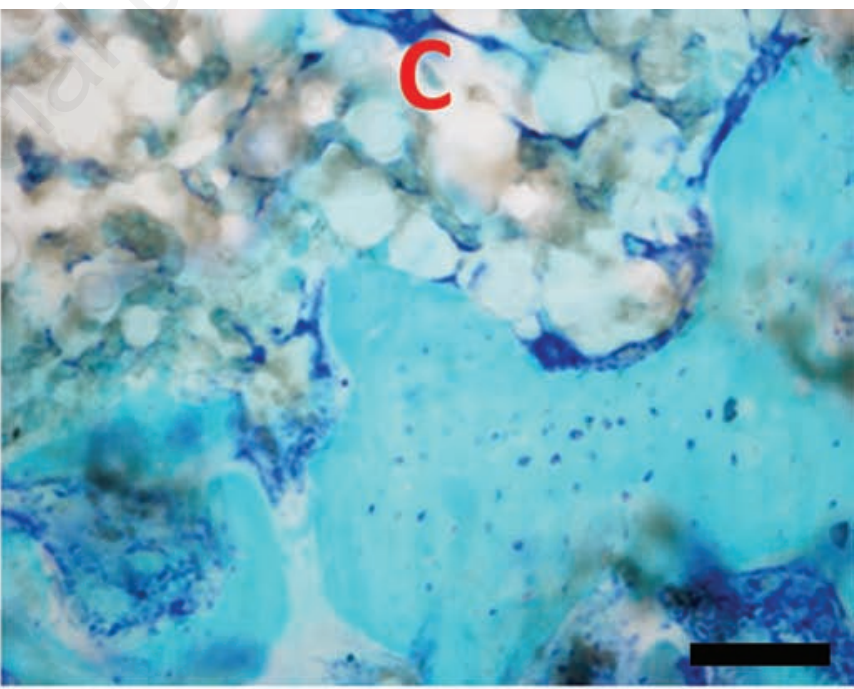

Figure 8. Histological sample of $P$ cement $(A)$ and enlarged particulars (B, C). Scale bars: A), $40 \mu \mathrm{m} ; \mathrm{B}, \mathrm{C}), 20 \mu \mathrm{m}$. 
analysis of the results. The increase of contact surface (probably due to the increased porosity of the cement) and the formation at the bonecement interface of newly formed trabecular bones with strands of connective tissue going deep into the superficial layer of the cement, prove the excellent osteointegration of the cement with the biological structures of the host. This, together with the low elastic modulus of the new porous cement, leads to potential advantages in terms of lighter wearing, greater elasticity and dynamic resistance to fatigue and collisions. $^{27}$ Porous cements made by TCP/PMMA could be considered for vertebroplastic or augmentation orthopaedics uses, but further studies are necessary in order to evaluate the mechanical properties of this material in vivo. The use of LR white resin to prepare samples of bone tissue subjected to injections of bone cements has proven to be able to obtain histological images of high quality. Simultaneously, the use of SEM allows an objective measure of the pores, eventually present in the bone cement. The present work shows that the proposed procedure for the evaluation of biocompatibility, based on the use of LR white resin and the use of (SEM) allows making a thorough and objective assessment of the biocompatibility of porous $v s$ non-porous bone cements.

\section{References}

1. Charnley J. Anchorage of the femoral Head prosthesis to the shaft of the femur. J Bone Joint Surg Br 1960;42:28-30.

2. Galibert P, Deramond H, Rosat P, Le Gars D. Preliminary note on the treatment of vertebral angioma by percutaneous acrylic vertebroplasty. Neurochirurgie 1987;33:166-8.

3. Harrington KD. The use of methylmethacrylate for vertebral-body replacement and anterior stabilization of pathological fracture-dislocations of the spine due to metastatic malignant disease. J Bone Joint Surg Am 1981;63:36-46.

4. Cohen JE, Lylyk P, Ceratto R, Kaplan L, Umanskyt F, Gomori JM. Percutaneous vertebroplasty: technique and results in 192 procedures. Neurol Res 2004;26:41-9.

5. Heini PF, Wälchli B, Berlemann U. Percutaneus transpedicular vertebroplasty with PMMA: operative technique and early results. A prospective study for the treatment of ostheoporotic compression fractures. Eur Spine J 2000;9:445-50.

6. Thillainadesan J, Schlaphoff G, Gibson KA. Long term outcomes of vertebroplasty for osteoporotic compression fractures. J Med Imaging Radiat Oncol 2010;54:307-14.

7. Mazumdar A, Gilula LA. Relief of radicular pain in metastatic disease by vertebroplasty.
Acta Radiol 2010;51:179-82.

8. Dall'Oca C, Maluta T, Moscolo A, Lavini F, Bartolozzi P. Cement augmentation of intertrochanteric fractures stabilised with intramedullary nailing. Injury 2010;41:1150-5.

9. Jaeblon T. Polymethylmethacrylate: properties and contemporary uses in orthopaedics. J Am Acad Orthop Surg 2010;18:297-305.

10. Dahl OE, Garvik LJ, Lyberg T. Toxic effects of methylmethacrylate monomer on leukocytes and endothelial cells in vitro. Acta Orthop Scand 1994;65:147-53.

11. Deramon H, Wright NT, Belkoff SM. Temperature elevation caused by bone cement polymerization during vertebroplasty. Bone 1999;25:17S-21S.

12. Leeson MC, Lippitt SB. Thermal aspects of the use of polymethylmethacrylate in large metaphyseal defects in bone. A clinical review and laboratory study. Clin Orthop Relat Res 1993:295:239-45.

13. Freeman MA, Bradley GW, Revel PA. Observation upon the interface between bone, polymethylmethacrylate cement. J Bone Joint Surg Br 1982;64:489-93.

14. Goldring SR, Schiller AL, Roelke M, Rourke CM, O'Neil DA, Harris WH. The synovial-like membrane at the bone-cement interface in loose total hip replacements and its proposed role in bone lysis. J Bone Joint Surg Am 1983;65:575-84.

15. Harper EJ. Bioactive bone cements. Proc Inst Mech Eng H 1998;212:113-20.

16. Takagi S, Chow LC, Ishikawa K. Formation of hydroxyapatite in new calcium phosphate cements. Biomaterials 1998;19:1593-9.

17. Yokoyama A, Yamamoto S, Kawasaki T, Kohgo T, Nakasu M. Development of calcium phosphate cement using chitosan and citric acid for bone substitute materials. Biomaterials 2002;23:1091-101.

18. Xu HH, Simon CG Jr. Fast setting calcium phosphate-chitosan scaffold: mechanical properties and biocompatibility. Biomaterials 2005;26:1337-48.

19. Burguera EF, Xu HH, Weir MD. Injectable and rapid-setting calcium phosphate bone cement with dicalcium phosphate dehydrate. J Biomed Mater Res B Appl Biomater 2006;77:126-34.

20. Klein CP, de Groot K, Driessen AA, van der Lubbe HB. Interaction of biodegradable betawhitlockite ceramics with bone tissue: an in vivo study. Biomaterials 1985;6:189-92.

21. Wang $X$, Ye J, Wang Y. Influence of a novel radiopacifier on the properties of an injectable calcium phosphate cement. Acta Biomater 2007;3:757-63.

22. Goto K, Shinzato S, Fujibayashi S, Tamura J, Kawanabe K, Hasegawa S, et al. The biocompatibility and osteoconductivity of a cement containing beta-TCP for use in vertebroplasty. J Biomed Mater Res A 2006;78:629-37.
23. Goto K, Kawanabe K, Kowalski R, Baker D, Nakamura T. Bonding ability evaluation of bone cement on the cortical surface of rabbit's tibia. J Mater Sci Mater Med 2010;21:139-46.

24. Fini M, Giavaresi G, Aldini NN, Torricelli P, Botter R, Beruto D, et al. A bone substitute composed of polymethylmetacrilate and alpha-tricalcium phosphate; results in terms of osteoblast function and bone tissue formation. Biomaterials 2002;23:4523-31.

25. Sbarbati A, Accorsi D, Benati D, Marchetti L, Orsini G, Rigotti G, et al. Subcutaneous adipose tissue classification. Eur $\mathrm{J}$ Histochem 2010;54:e48.

26. Zaffe D. Some considerations on biomaterials and bone. Micron 2005;36:583-92.

27. Wagoner Johnson AJ, Herschler BA. A review of the mechanical behavior of $\mathrm{CaP}$ and $\mathrm{CaP} /$ polymer composites for applications in bone replacement and repair. Acta Biomater 2011;7:16-30.

28. Tamura J, Kawanabe K, Kobayashi M, Nakamura T, Kokubo T, Yoshihara S, et al. Mechanical and biological properties of two types of bioactive bone cements containing $\mathrm{MgO}-\mathrm{CaO}-\mathrm{SiO2}-\mathrm{P} 205-\mathrm{CaF}$, glass and glassceramic powder. J Biomed Mater Res 1996;30:85-94.

29. Lopes PP, Garcia MP, Fernandes MH, Fernandes MH. Acrylic formulations containing bioactive and biodegradable filler sto be used as bone cements: properties and biocompatibily assessment. Mater Sci Eng C Mater Biol Appl 2013;33:1289-99.

30. Von Rechenberg B, Génot OR, Nuss K, Galuppo L, Fulmer M, Jacobson E, et al. Evaluation of four biodegradable, injectable bone cements in an experimental drill hole model in sheep. Eur J Pharm Biopharm 2013;85:130-8.

31. Tuzuner T, Sencan I, Ozdemir D, Alper M, Duman S, Yavuz T, et al. In vivo evaluation of teicoplanin- and calcium sulfate-loaded PMMA bone cement in preventing implantrelated osteomyelitis in rats. $\mathrm{J}$ Chemother 2006;18:628-33.

32. Machado JL, Giehl IC, Nardi NB, dos Santos LA. Evaluation of scaffolds based on $\alpha$-tricalcium phosphate cements for tissue engineering application. IEEE Trans Biomed Eng 2011;58:1814-9.

33. Kobayashi M, Nakamura T, Okada Y, Fukumoto A, Furukawa T, Kato H, et al. Bioactive bone cement: comparison of apatite and wollastonite containing glass-ceramic, hydrossiapatite, and beta-tricalcium phosphate fillers on bone-bonding strength. J Biomed Mater Res 1998;42:223-37.

34. Wong CT, Lu WW, Chan WK, Cheung KM, Luk $\mathrm{KD}$, Lu DS, et al. In vivo cancellous bone remodeling on strontium-containing hydroxyapatite (sr-HA) bioactive cement. J Biomed Mater Res A 2004;68:513-21. 